\title{
Pemodelan Bangkitan Dan Tarikan Perjalanan Moda Sepeda Motor Di Wilayah Perkotaan Gresik Tahun 2018
}

\author{
Modelling Trip Production and Trip Attraction of Motorcycle Trip \\ in Gresik Urban Areas for Year 2018
}

\author{
Jimi Amijaya ${ }^{1, a)}$ \& Hitapriya Suprayitno ${ }^{2, b)}$ \\ ${ }^{1)}$ Mahasiswa Teknik Sipil, Institut Teknologi Sepuluh Nopember (ITS), Surabaya. \\ ${ }^{2)}$ Departemen Teknik Sipil, Institut Teknologi Sepuluh Nopember (ITS), Surabaya.
}

Koresponden : a)jimiamijaya@gmail.com \& b) suprayitno.hita@gmail.com

\begin{abstract}
ABSTRAK
Kota Gresik sebagai ibu kota Kabupaten Gresik Provinsi Jawa Timur dikenal sebagai kota industri, pertumbuhan dan perkembangannya cukup meningkat setiap tahun. Terdapat banyak pergerakan arus lalu lintas khususnya jam puncak pagi menggunakan moda sepeda motor, hal tersebut dikarenakan jam berangkat kerja bersamaan dengan berangkat sekolah dan mengakibatkan permasalahan transportasi semakin kompleks. Oleh karena itu diperlukan penelitian mengenai pemodelan bangkitan dan tarikan perjalanan moda sepeda motor yang terjadi di wilayah perkotaan Gresik. Metoda yang dipakai adalah pengumpulan data primer dan sekunder. Data primer didapatkan dari survei wawancara rumah tangga (household interview) untuk mendapatkan data asal tujuan perjalanan sebanyak 700 sampel. Sedangkan data sekunder berupa data populasi dan kuat tarik zona dari Gresik Dalam Angka 2016. Penelitian ini menghasilkan jumlah bangkitan dan tarikan sepeda motor. Bangkitan perjalanan didapatkan dari perhitungan analisa regresi linier zona untuk mendapatkan rumus yang akan menghasilkan jumlah bangkitan perjalanan. Hasil bangkitan perjalanan terbanyak sejumlah 15.906 motor/jam di zona 16. Tarikan perjalanan didapatkan dari perhitungan proporsi kuat tarik dikalikan dengan bangkitan perjalanan. Hasil dari tarikan perjalanan terbanyak sejumlah 22.095 motor/jam di zona 17.
\end{abstract}

Kata Kunci : manajemen aset infrastruktur, jaringan jalan, perencanaan, pemodelan, bangkitan dan tarikan perjalanan, motor, wilayah perkotaan Gresik

\section{PENDAHULUAN}

Salah satu tugas Manajemen Aset Infrastruktur (MAI) adalah menilai kecukupan dan kualitas jaringan jalan (Suprayitno \& Soemitro, 2018). Pada perhitungan model jaringan jalan dibutuhkan Pemodelan Bangkitan dan Tarikan Perjalanan guna mendapatkan nilai bangkitan dan tarikan perjalanan.

Kota Gresik sebagai ibu kota Kabupaten Gresik Provinsi Jawa Timur, dalam perkembangan setiap tahunnya cukup pesat. Dimana sebagai ibukota Kabupaten dan juga sebagai pusat pemerintahan, kota Gresik dikenal sebagai kota industri karena sangat banyak berdiri pabrik dan perindustrian. Pertumbuhan dan perkembangan yang meningkat menuntut masyarakat untuk melakukan interaksi pergerakan dengan berbagai pihak di berbagai tempat. Semakin meningkatnya pergerakan lalu lintas, maka permasalahan transportasi juga semakin kompleks. Terdapat banyak arus lalu lintas yang terjadi di wilayah perkotaan Gresik, khususnya jam puncak pagi. Hal tersebut dikarenakan jam berangkat kerja bersamaan dengan jam berangkat sekolah. 
Banyaknya perindustrian di wilayah perkotaan Gresik ini mengakibatkan tingginya jumlah pekerja yang menuju maupun meninggalkan tempat kerja. Dan di sisi lain adanya aktifitas dari sekolah maupun perguruan tinggi yang ada di wilayah perkotaan Gresik. Hal tersebut sangat berpotensi mengakibatkan kemacetan lalu lintas khususnya sepeda motor, karena saat ini memang moda tersebut yang jumlahnya sangat dominan. Berdasarkan data dari Gresik Dalam Angka 2016 bahwa tercatat 2.709 industri, 171 sekolah dan 152.200 kepemilikan sepeda motor.

Oleh karena itu tujuan dari penelitian ini adalah untuk memodelkan Bangkitan dan Tarikan Perjalanan, dan menghitung jumlah bangkitan perjalanan yang terdiri dari pergerakan yang dibangkitkan oleh daerah atau zona asal (bangkitan perjalanan) dan pergerakan yang tertarik ke suatu daerah atau zona tujuan (tarikan perjalanan) di wilayah perkotaan Gresik.

\section{STUDI PUSTAKA}

\section{Definisi Bangkitan Perjalanan}

Tahapan bangkitan perjalanan bertujuan mendapatkan jumlah pergerakan yang dibangkitkan oleh setiap zona asal (Oi) ke zona tujuan (Dd) yang ada di dalam daerah kajian. Proses estimasi pada tahapan ini umumnya menggunakan data yang didapat dari Survei Rumah Tangga (household interview survei) yang dijadikan dasar dalam mengidentifikasi zona asal dan zona tujuan pergerakan dalam daerah kajian. Ada beberapa metode yang dikenal dalam proses perhitungan bangkitan perjalanan, yaitu : 1). Analisa Regresi Linier Zona; 2). Klasifikasi Silang (Ortuzar \& Willumsen, 1990). Gambar 1 menunjukkan penggambaran Bangkitan Perjalanan yang berasal dari zona i.

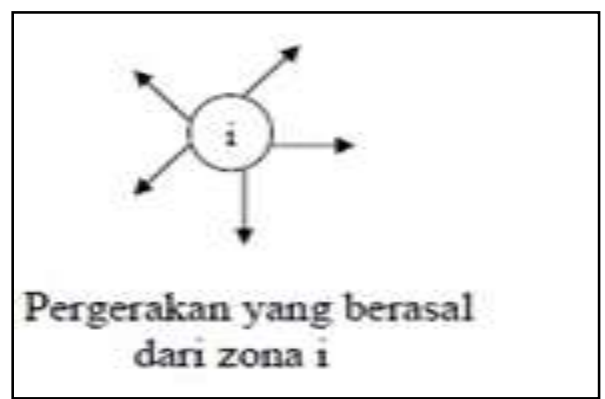

Gambar 1. Penggambaran Bangkitan Perjalanan

\section{Definisi Tarikan Perjalanan}

Tarikan perjalanan adalah tahapan pemodelan yang memperkirakan jumlah pergerakan yang tertarik ke suatu tata guna lahan atau zona. Tarikan perjalanan mencakup pergerakan lalu lintas yang menuju atau tiba ke suatu lokasi. Tarikan lalu lintas tersebut tergantung pada dua aspek tata guna lahan, yaitu jenis dan jumlah aktivitas / intensitas pada tata guna lahan tersebut. Gambar 2 menunjukkan penggambaran Tarikan Perjalanan yang menuju zona j. (Tamin, 2008).

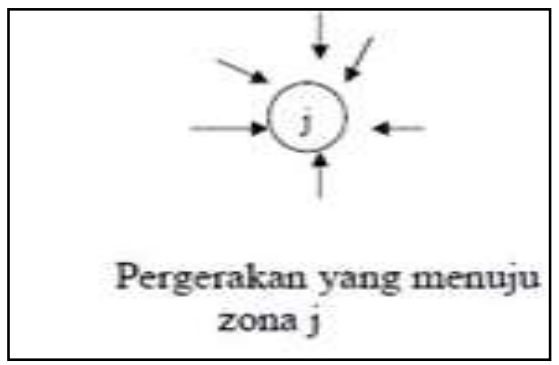

Gambar 2. Penggambaran Tarikan Perjalanan 


\section{Survei Wawancara Rumah Tangga}

Survei wawancara rumah tangga (Household Interview Survei) adalah salah satu jenis yang paling diandalkan dari survei untuk memperoleh data asal dan tujuan. Survei ini dasarnya dimaksudkan untuk menghasilkan data pada pola perjalanan dan karakteristik umum dari rumah tangga mempengaruhi dalam perjalanan. Informasi pada pola perjalanan meliputi jumlah perjalanan dibuat asal mereka dan tujuan, tujuan perjalanan, jenis perjalanan, waktu keberangkatan dari asal dan waktu kedatangan di tujuan dan sebagainya. Informasi pada karakteristik rumah tangga termasuk jenis hunian unit, jumlah penduduk, usia, jenis kelamin, kepemilikan kendaraan, jumlah pengguna kendaraan, pendapatan keluarga dan seterusnya. (Tamin, 2008).

\section{Model Transportasi 4 Tahap}

Model yang baik adalah model yang bisa menggambarkan semua faktor yang mewakili perilaku manusia. Akan tetapi, kemampuan pemodelan yang dibatasi waktu dan biaya menyebabkan sulitnya menghasilkan model yang lengkap. Secara praktis dibutuhkan berbagai macam jenis model untuk berbagai tujuan dan pemecahan permasalahan tertentu. Konsep perencanaan transportasi yang telah berkembang saat ini dan yang paling popular adalah Model Perencanaan Transportasi 4 Tahap. Adapun tahap dari model tersebut adalah Trip Generation, Modal Split, Trip Distribution dan Trip Assignment. Dalam suatu pembuatan model terdapat beberapa hal yang sangat mempengaruhi tingkat keberhasilan, yaitu penentuan zona dan jumlah sampel. (Tamin, 2008).

\section{Model Bangkitan}

Penentuan persamaan Model Bangkitan dibentuk dari hubungan antara jumlah kepemilikan motor dengan jumlah perjalanan (trip) motor di wilayah kota Samarinda, dan data yang diperoleh adalah dari survei rumah tangga (HIS). Untuk membuat persamaan bangkitan perjalanan perlu adanya grafik hubungan antara jumlah kepemilikan motor dengan jumlah trip motor menggunakan analisa regresi linier. Berdasarkan grafik model bangkitan perjalanan, telah diketahui bahwa semakin banyak jumlah sepeda motor maka semakin banyak pula jumlah trip yang akan terjadi. Gambar 3 menunjukkan grafik bangkitan perjalanan motor di wilayah kota Samarinda dengan hasil $\mathrm{TP}_{\mathrm{sm}}=0,9372 \mathrm{x}+3,3986$ dan $\mathrm{R}^{2}=$ 0,9658 (Praditya, 2017).

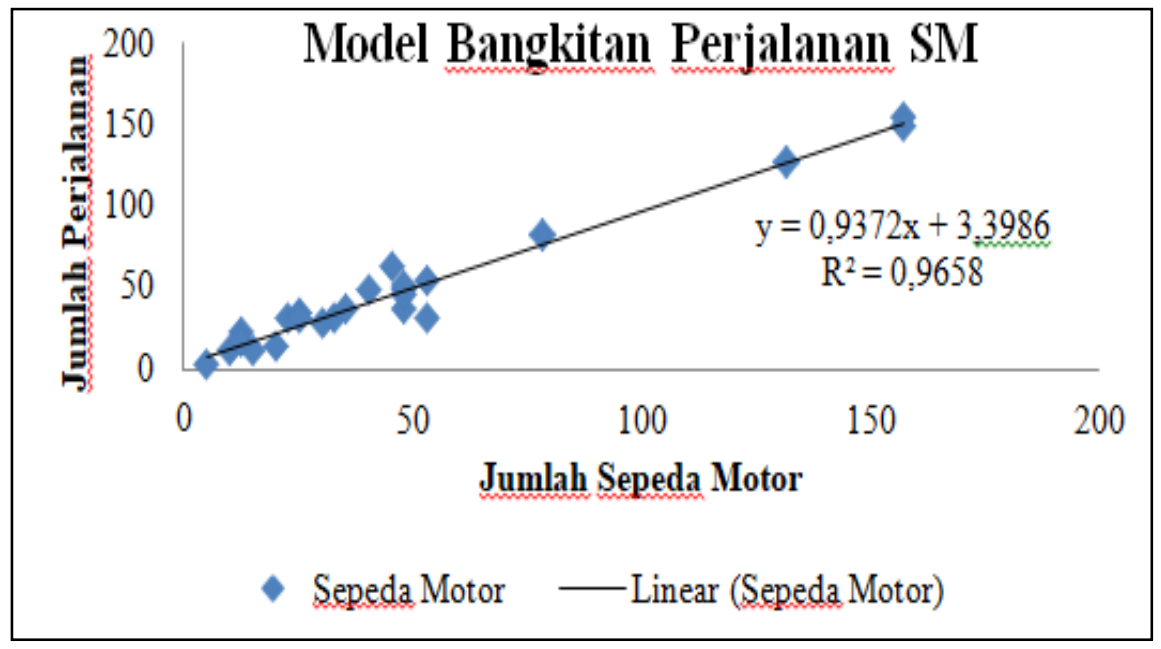

Gambar 3. Grafik Model Bangkitan Perjalanan Motor Sumber : Praditya, 2017 


\section{Model Tarikan}

Perhitungan persamaan tarikan perjalanan (Trip Attraction) merupakan salah satu perhitungan yang digunakan dalam perhitungan Trip Generation. Tarikan perjalanan menggunakan proporsi nilai kuat tarik tiap zona kelurahan / desa yang akan dikalikan dengan total bangkitan perjalanan. Nilai kuat tarik di dapat dari jenis wilayah zona, hasilnya sebagian besar peruntukannya adalah pusat perindustrian dan sekolah yang menyebabkan tarikan tinggi di zona tersebut. (Tamin, 2008).

\section{PENGUMPULAN DATA}

Metode yang digunakan pada perhitungan Bangkitan dan Tarikan Perjalanan ini adalah dengan pengumpulan data primer berupa survei wawancara rumah tangga yang berisikan data asal tujuan perjalanan. Sedangkan pada data sekunder berupa data jumlah kepemilikan kendaraan dan data administrasi wilayah. Dari pengolahan data primer tersebut akan menghasilkan bangkitan perjalanan. Sedangkan pada pengolahan data sekunder akan dihasilkan tarikan perjalanan.

\section{ANALISIS PENELITIAN}

\section{Hasil Survei Wawancara Rumah Tangga}

Survei wawancara rumah tangga (household interview) adalah survei wawancara langsung ke rumah warga dengan jumlah 700 sampel yang dilakukan pada 25 zona. Adapun data yang digunakan dari survei tersebut untuk perhitungan Bangkitan Perjalanan adalah sebagai berikut : 1). Jumlah anggota yang tinggal, 2). Jumlah kepemilikan sepeda motor, 3). Jumlah perjalanan yang dilakukan menggunakan sepeda motor. Data tersebut direkap dan ditunjukkan pada Tabel 1.

Tabel 1. Hasil Survei Wawancara Rumah Tangga

\begin{tabular}{|c|c|c|c|c|c|}
\hline \multirow[b]{2}{*}{ NO } & \multirow[b]{2}{*}{ ZONA } & \multirow[b]{2}{*}{$\begin{array}{l}\text { RUMAH } \\
\text { TANGGA }\end{array}$} & \multicolumn{3}{|c|}{ DATA RUMAH TANGGA } \\
\hline & & & $\begin{array}{c}\text { Anggota } \\
\text { Yang Tinggal }\end{array}$ & $\begin{array}{l}\text { Jumlah } \\
\text { Motor }\end{array}$ & $\begin{array}{l}\text { Trip } \\
\text { Motor }\end{array}$ \\
\hline 1 & Zona 1 & 6 & 16 & 9 & 7 \\
\hline 2 & Zona 2 & 11 & 33 & 22 & 18 \\
\hline 3 & Zona 3 & 2 & 7 & 3 & 3 \\
\hline 4 & Zona 4 & 1 & 4 & 2 & 2 \\
\hline 5 & Zona 5 & 22 & 63 & 26 & 29 \\
\hline 6 & Zona 6 & 29 & 88 & 50 & 48 \\
\hline 7 & Zona 7 & 5 & 12 & 8 & 7 \\
\hline 8 & Zona 8 & 15 & 45 & 26 & 22 \\
\hline 9 & Zona 9 & 18 & 55 & 36 & 30 \\
\hline 10 & Zona 10 & 69 & 266 & 136 & 122 \\
\hline 11 & Zona 11 & 6 & 17 & 11 & 9 \\
\hline 12 & Zona 12 & 30 & 89 & 53 & 45 \\
\hline 13 & Zona 13 & 2 & 4 & 4 & 2 \\
\hline 14 & Zona 14 & 2 & 7 & 4 & 2 \\
\hline 15 & Zona 15 & 34 & 101 & 68 & 55 \\
\hline 16 & Zona 16 & 108 & 315 & 216 & 184 \\
\hline 17 & Zona 17 & 5 & 16 & 17 & 11 \\
\hline 18 & Zona 18 & 43 & 131 & 100 & 66 \\
\hline 19 & Zona 19 & 4 & 14 & 11 & 7 \\
\hline 20 & Zona 20 & 25 & 103 & 49 & 43 \\
\hline 21 & Zona 21 & 150 & 507 & 244 & 253 \\
\hline 22 & Zona 22 & 58 & 192 & 133 & 88 \\
\hline 23 & Zona 23 & 34 & 134 & 73 & 55 \\
\hline 24 & Zona 24 & 5 & 14 & 12 & 5 \\
\hline 25 & Zona 25 & 16 & 64 & 46 & 28 \\
\hline \multicolumn{2}{|c|}{ Total } & 700 & 2297 & 1359 & 1141 \\
\hline
\end{tabular}




\section{Pemodelan Bangkitan Sepeda Motor}

Tahapan awal dalam perhitungan Bangkitan Perjalanan adalah mendapatkan model bangkitan sepeda motor. Hal pertama yang harus dilakukan adalah membuat persamaan dari bangkitan perjalanan yang akan digunakan dalam perhitungan tarikan perjalanan. Ada 2 metode yang dapat dipakai untuk mencari persamaan tersebut : 1) Persamaan dari hubungan antara jumlah kepemilikan sepeda motor dengan jumlah perjalanan sepeda motor yang di dapat dari data survei wawancara rumah tangga, 2) Persamaan dari hubungan antara jumlah anggota yang tinggal dengan jumlah perjalanan sepeda motor yang di dapat dari data survei wawancara rumah tangga (Suprayitno, 2018). Hasil grafik dari persamaan ke-1 dapat dilihat pada Gambar 4. Sedangkan hasil grafik dari persamaan ke-2 dapat dilihat pada Gambar 5.

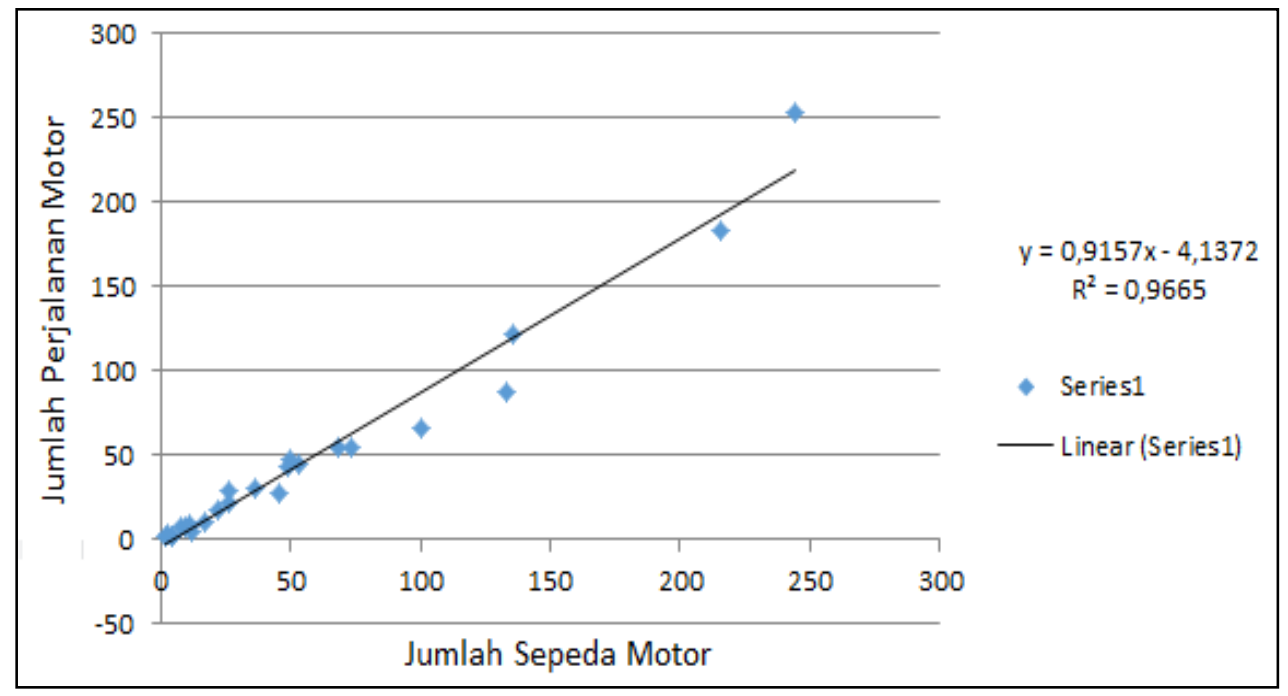

Gambar 4. Grafik Trip Bangkitan Perjalanan menggunakan Persamaan Jumlah Motor

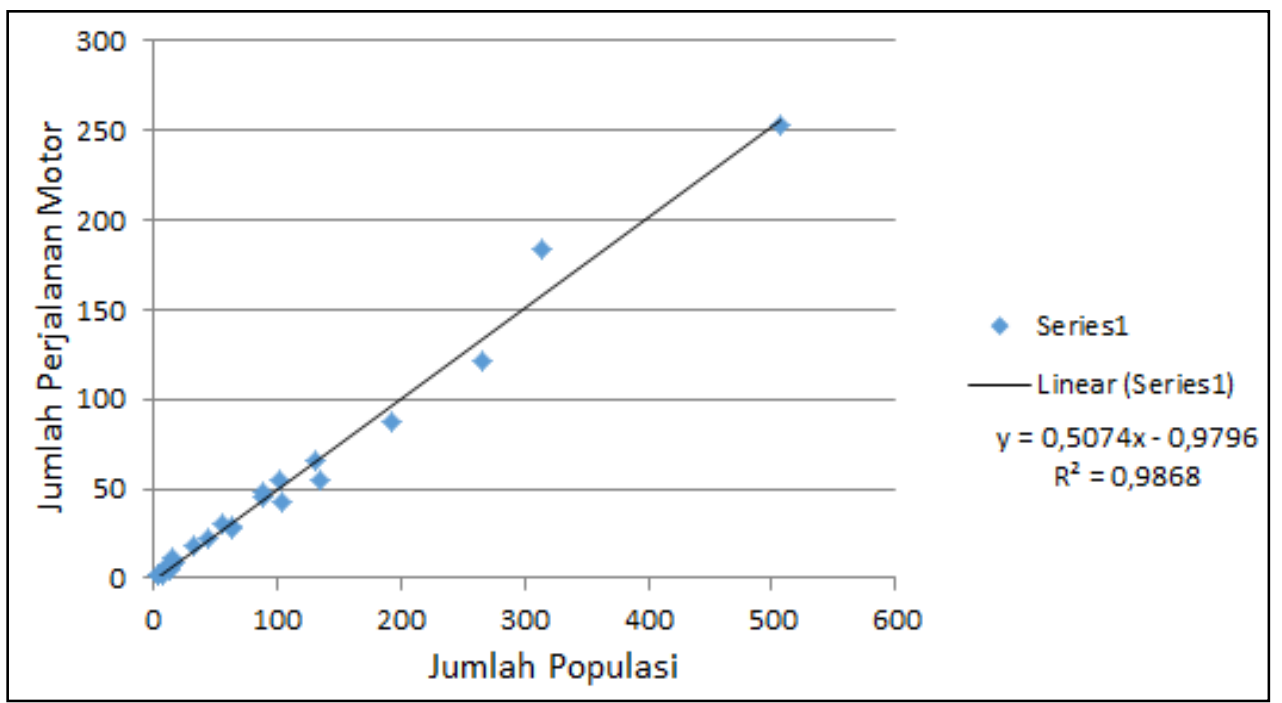

Gambar 5. Grafik Bangkitan Perjalanan menggunakan Persamaan Jumlah Populasi

$$
\begin{aligned}
& \mathrm{TP}_{\mathrm{sm}, \mathrm{sm}}=0,9157 \mathrm{SM}-4,1372 \\
& \mathrm{R}^{2}=0,9665 \\
& \mathrm{TP}_{\text {sm,pop }}=0,5074 \mathrm{POP}-0,9796 \\
& \mathrm{R}^{2}=0,9868
\end{aligned}
$$


Dimana :

$$
\begin{array}{ll}
\text { TPsm }, \text { sm } & =\text { Bangkitan Perjalanan berbasis jumlah sepeda motor } \\
\text { TPsm,pop } & =\text { Bangkitan Perjalanan berbasis jumlah populasi } \\
\text { SM } & =\text { Jumlah Sepeda Motor } \\
\text { POP } & =\text { Jumlah Populasi } \\
\mathrm{R}^{2} & =\text { Koefisien Determinasi }
\end{array}
$$

Berdasarkan kedua grafik bangkitan perjalanan sepeda motor diatas dapat diketahui bahwa semakin banyak jumlah kepemilikan sepeda motor maka semakin banyak pula jumlah perjalanan yang terjadi. Dari kedua grafik diatas dapat dilihat bahwa hasil terbaik pada Persamaan ke-2 dengan ditunjukkan $\mathrm{R}^{2}=0,9868$, namun berdasarkan studi pustaka yang benar dan yang sebagian besar penerapannya dipakai adalah menggunakan persamaan ke-1 yaitu persamaan antara jumlah kepemilikan sepeda motor dengan jumlah perjalanan sepeda motor. Maka persamaan yang digunakan dalam perhitungan selanjutnya adalah $T P_{s m}=0,9157 S M-4,1372$ dengan $R^{2}=0,9665$.

\section{Perhitungan Bangkitan Perjalanan}

Perhitungan Bangkitan perjalanan (trip production) menggunakan persamaan regresi linier zona yang telah ditunjukkan pada Gambar 4 berupa grafik bangkitan perjalanan yang menghasilkan rumus bangkitan perjalanan. Dalam perhitungan bangkitan perjalanan, jumlah kepemilikan sepeda motor memiliki peran yang penting untuk menentukan jumlah bangkitan perjalanan. Semakin banyak jumlah kepemilikan sepeda motor dalam suatu zona, maka semakin besar pula jumlah bangkitan perjalanan dalam zona tersebut. Berikut adalah hasil perhitungan bangkitan perjalanan (trip production) ditunjukkan pada Tabel 2.

Tabel 2. Hasil Bangkitan Perjalanan

\begin{tabular}{|r|r|r|r|r|}
\hline \multicolumn{2}{|c|}{ Trip Production } & \multicolumn{2}{c|}{ TPsm,sm=0.9157 SM - 4.1372 } \\
\hline \hline No & Zona & $\begin{array}{c}\text { Populasi } \\
\text { (Jiwa) }\end{array}$ & $\begin{array}{c}\text { Jumlah Motor } \\
\text { (Unit) }\end{array}$ & $\begin{array}{c}\text { Trip } \\
\text { Production } \\
\text { Motor }\end{array}$ \\
\hline \hline 1 & Zona 1 & 1694 & 935 & 852 \\
\hline 2 & Zona 2 & 7858 & 6592 & 6032 \\
\hline 3 & Zona 3 & 5182 & 3021 & 2762 \\
\hline 4 & Zona 4 & 2802 & 1268 & 1157 \\
\hline 5 & Zona 5 & 5397 & 4120 & 3769 \\
\hline 6 & Zona 6 & 19526 & 11102 & 10162 \\
\hline 7 & Zona 7 & 7761 & 5191 & 4749 \\
\hline 8 & Zona 8 & 10974 & 6986 & 6393 \\
\hline 9 & Zona 9 & 7687 & 5144 & 4706 \\
\hline 10 & Zona 10 & 18053 & 11614 & 10631 \\
\hline 11 & Zona 11 & 5533 & 4210 & 3851 \\
\hline 12 & Zona 12 & 9104 & 7013 & 6418 \\
\hline 13 & Zona 13 & 8034 & 6215 & 5687 \\
\hline 14 & Zona 14 & 7440 & 3377 & 3088 \\
\hline 15 & Zona 15 & 14047 & 6405 & 5861 \\
\hline 16 & Zona 16 & 24245 & 17375 & 15906 \\
\hline 17 & Zona 17 & 7205 & 2774 & 2536 \\
\hline 18 & Zona 18 & 9676 & 5682 & 5199 \\
\hline 19 & Zona 19 & 4202 & 1692 & 1545 \\
\hline 20 & Zona 20 & 14206 & 9209 & 8429 \\
\hline 21 & Zona 21 & 16514 & 10267 & 9397 \\
\hline 22 & Zona 22 & 12712 & 7590 & 6946 \\
\hline 23 & Zona 23 & 9288 & 6032 & 5519 \\
\hline 24 & Zona 24 & 5681 & 3126 & 2858 \\
\hline 25 & Zona 25 & 9842 & 5260 & 4812 \\
\hline \hline & Total & 244663 & 152200 & 139266 \\
\hline & & & & \\
\hline
\end{tabular}




\section{Perhitungan Proporsi Kuat Tarik}

Perhitungan proporsi kuat tarik adalah metode dimana untuk menghitung tarikan perjalanan (trip attraction) yang terjadi di suatu zona. Kuat tarik ini berdasarkan peruntukan wilayah setempat yang beraktifitas menimbulkan suatu tarikan. Dalam kasus kali ini karena menggunakan jam puncak pagi maka sebagian besar yang menimbulkan tarikan perjalanan adalah tempat pendidikan (sekolah) dan perindustrian (pabrik), dikarenakan wilayah perkotaan Gresik merupakan kota industri. Berikut adalah hasil perhitungan proporsi kuat tarik ditunjukkan pada Tabel 3.

Tabel 3. Hasil Proporsi Kuat Tarik

\begin{tabular}{|c|c|c|c|c|c|c|c|c|c|c|c|c|c|c|c|c|}
\hline \multirow{3}{*}{ No } & \multirow{3}{*}{ Zona } & \multicolumn{3}{|c|}{ Industri } & \multicolumn{5}{|c|}{ Sekolah Negeri } & \multicolumn{5}{|c|}{ Sekolah Swasta } & \multirow{3}{*}{$\begin{array}{l}\text { Total } \\
\text { Tiap } \\
\text { Zona }\end{array}$} & \multirow{3}{*}{\begin{tabular}{|c|} 
Kuat \\
Tarik
\end{tabular}} \\
\hline & & \multirow{2}{*}{\begin{tabular}{|l|} 
kecil \\
pekerja \\
\end{tabular}} & \multirow{2}{*}{\begin{tabular}{|l} 
Sedang \\
pekerja
\end{tabular}} & \multirow{2}{*}{\begin{tabular}{|l} 
Besar \\
pekerja
\end{tabular}} & \multirow{2}{*}{$\begin{array}{c}\text { TK } \\
\text { siswa/i }\end{array}$} & \multirow{2}{*}{\begin{tabular}{|c|} 
SD \\
siswa/i \\
\end{tabular}} & \multirow{2}{*}{\begin{tabular}{|l|} 
SMP \\
siswa/i
\end{tabular}} & \multirow{2}{*}{$\begin{array}{l}\text { SMA } \\
\text { siswa/i }\end{array}$} & \multirow{2}{*}{$\begin{array}{c}\text { PT } \\
\text { siswa/i }\end{array}$} & \multirow{2}{*}{\begin{tabular}{|c|} 
TK \\
siswa/i \\
\end{tabular}} & \multirow{2}{*}{\begin{tabular}{|c|} 
SD \\
siswa/i
\end{tabular}} & \multirow{2}{*}{\begin{tabular}{l|l} 
SMP \\
siswa/i
\end{tabular}} & \multirow{2}{*}{$\begin{array}{l}\text { SMA } \\
\text { siswa/i }\end{array}$} & \multirow{2}{*}{$\begin{array}{c}\text { PT } \\
\text { siswa/i }\end{array}$} & & \\
\hline & & & & & & & & & & & & & & & & \\
\hline 1 & Zona 1 & 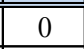 & 0 & 4000 & 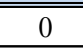 & 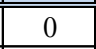 & 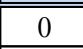 & 0 & 0 & 0 & 0 & 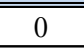 & 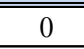 & 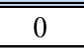 & 4000 & 40 \\
\hline 2 & \begin{tabular}{|l|} 
Zona 2 \\
\end{tabular} & 18 & 0 & 0 & 0 & 360 & 0 & 0 & 0 & 30 & 0 & 0 & 0 & 0 & 408 & \\
\hline 3 & Zona 3 & 0 & 0 & 7000 & 0 & 360 & 0 & 0 & 0 & 90 & 0 & 0 & 0 & 0 & 7450 & 7 \\
\hline 4 & \begin{tabular}{|l|} 
Zona 4 \\
\end{tabular} & 0 & 0 & 0 & 0 & 0 & 0 & 0 & 0 & 30 & 0 & 0 & 0 & 0 & 30 & \\
\hline 5 & \begin{tabular}{|l|} 
Zona 5 \\
\end{tabular} & 36 & 3000 & 0 & 0 & 360 & 0 & 0 & 0 & 30 & 0 & 0 & 0 & 0 & 3426 & 34 \\
\hline 6 & Zona 6 & 243 & 1000 & 0 & 0 & 360 & 0 & 0 & 0 & 150 & 1080 & 0 & 0 & 0 & 2833 & \\
\hline 7 & \begin{tabular}{|l|} 
Zona 7 \\
\end{tabular} & 159 & 2000 & 0 & 0 & 0 & 0 & 0 & 0 & 30 & 1080 & 0 & 0 & 0 & 3269 & 33 \\
\hline 8 & Zona 8 & 177 & 0 & 0 & 0 & 0 & 0 & 0 & 0 & 120 & 720 & 0 & 0 & 0 & 1017 & 4 \\
\hline 9 & \begin{tabular}{|l|} 
Zona 9 \\
\end{tabular} & 129 & 2000 & 0 & 0 & 720 & 0 & 0 & 0 & 60 & 0 & 0 & 0 & 0 & 2909 & \\
\hline 10 & Zona 10 & 123 & 1500 & 0 & 0 & 2880 & 0 & 0 & 0 & 300 & 0 & 0 & 0 & 1600 & 6403 & 6 \\
\hline 11 & Zona 11 & 78 & 0 & 0 & 0 & 360 & 0 & 0 & 0 & 60 & 0 & 840 & 0 & 1600 & 2938 & 2 \\
\hline 12 & Zona 12 & 267 & 0 & 0 & 0 & 360 & 0 & 1080 & 0 & 120 & 720 & 0 & 0 & 0 & 2547 & \\
\hline 13 & Zona 13 & 93 & 500 & 0 & 0 & 360 & 0 & 0 & 0 & 90 & 0 & 0 & 0 & 0 & 1043 & 10 \\
\hline 14 & Zona 14 & 207 & 500 & 8000 & 0 & 720 & 0 & 0 & 0 & 90 & 0 & 0 & 0 & 0 & 9517 & \\
\hline 15 & Zona 15 & 3357 & 2500 & 2000 & 0 & 360 & 840 & 0 & 0 & 150 & 360 & 840 & 0 & 0 & 10407 & 10 \\
\hline 16 & Zona 16 & 1599 & 4000 & 13000 & 0 & 1080 & 840 & 0 & 0 & 180 & 720 & 1680 & 1080 & 1600 & 25779 & 25 \\
\hline 17 & Zona 17 & 159 & 11500 & 19000 & 0 & 720 & 0 & 0 & 0 & 120 & 0 & 0 & 0 & 0 & 31499 & 31 \\
\hline 18 & Zona 18 & 147 & 0 & 2000 & 0 & 360 & 0 & 0 & 0 & 210 & 360 & 1680 & 1080 & 1600 & 7437 & - \\
\hline 19 & Zona 19 & 117 & 7000 & 13000 & 0 & 360 & 0 & 0 & 0 & 60 & 0 & 0 & 0 & 0 & 20537 & 205 \\
\hline 20 & Zona 20 & 255 & 1500 & 4000 & 0 & 720 & 0 & 0 & 0 & 120 & 0 & 0 & 0 & 0 & 6595 & 66 \\
\hline 21 & Zona 21 & 48 & 1000 & 0 & 0 & 360 & 0 & 1080 & 0 & 210 & 1440 & 1680 & 3240 & 3200 & 12258 & 123 \\
\hline 22 & Zona 22 & 75 & 0 & 0 & 0 & 360 & 0 & 0 & 0 & 90 & 720 & 840 & 0 & 0 & 2085 & 21 \\
\hline 23 & Zona 23 & 72 & 1000 & 0 & 0 & 360 & 0 & 0 & 0 & 60 & 360 & 840 & 0 & 0 & 2692 & 2 \\
\hline 24 & Zona 24 & 48 & 5000 & 14000 & 0 & 360 & 0 & 0 & 0 & 90 & 360 & 0 & 0 & 0 & 19858 & 195 \\
\hline 25 & Zona 25 & 159 & 4000 & 5000 & 0 & 720 & 840 & 0 & 0 & 90 & 720 & 0 & 0 & 0 & 11529 & 115 \\
\hline & Total & 7566 & \begin{tabular}{l|l}
48000 \\
\end{tabular} & 991000 & 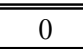 & 12600 & 2520 & 2160 & 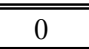 & 2580 & 8640 & 8400 & ב5400 & 96000 & 198466 & 198 \\
\hline
\end{tabular}

\section{Perhitungan Tarikan Perjalanan}

Perhitungan Tarikan Perjalanan (trip attraction) merupakan tahap lanjutan dari perhitungan bangkitan perjalanan. Perhitungan tarikan perjalanan menggunakan nilai kuat tarik di tiap zona yang akan dikalikan dengan hasil dari bangkitan perjalanan (trip production). Nilai kuat tarik didapatkan dari asumsi jumlah yang menuju tempat pendidikan (sekolah) dan perindustrian (pabrik) yang ditunjukkan pada Tabel 3 diatas. Jika dalam suatu zona tersebut terdapat sekolah atau pun industri di dalamnya, maka zona tersebut akan lebih banyak menarik perjalanan. Sedangkan apabila dalam zona tersebut hanya didominasi oleh rumah resident, maka zona tersebut hanya menarik sedikit perjalanan. Berikut adalah hasil perhitungan tarikan perjalanan ditunjukkan pada Tabel 4. 
Tabel 4. Hasil Tarikan Perjalanan

\begin{tabular}{|c|c|r|r|r|}
\hline \multicolumn{5}{|c|}{ Trip Attraction } \\
\hline \hline No & Zona & $\begin{array}{c}\text { Kuat } \\
\text { Tarik }\end{array}$ & $\begin{array}{c}\text { Trip } \\
\text { Production } \\
\text { Motor }\end{array}$ & $\begin{array}{c}\text { Trip } \\
\text { Attraction } \\
\text { Motor }\end{array}$ \\
\hline \hline 1 & Zona 1 & 40 & 852 & 2806 \\
\hline 2 & Zona 2 & 4 & 6032 & 286 \\
\hline 3 & Zona 3 & 75 & 2762 & 5226 \\
\hline 4 & Zona 4 & 1 & 1157 & 70 \\
\hline 5 & Zona 5 & 34 & 3769 & 2403 \\
\hline 6 & Zona 6 & 28 & 10162 & 1987 \\
\hline 7 & Zona 7 & 33 & 4749 & 2293 \\
\hline 8 & Zona 8 & 10 & 6393 & 713 \\
\hline 9 & Zona 9 & 29 & 4706 & 2041 \\
\hline 10 & Zona 10 & 64 & 10631 & 4491 \\
\hline 11 & Zona 11 & 29 & 3851 & 2061 \\
\hline 12 & Zona 12 & 25 & 6418 & 1787 \\
\hline 13 & Zona 13 & 10 & 5687 & 732 \\
\hline 14 & Zona 14 & 95 & 3088 & 6676 \\
\hline 15 & Zona 15 & 104 & 5861 & 7300 \\
\hline 16 & Zona 16 & 258 & 15906 & 18083 \\
\hline 17 & Zona 17 & 315 & 2536 & 22095 \\
\hline 18 & Zona 18 & 74 & 5199 & 5217 \\
\hline 19 & Zona 19 & 205 & 1545 & 14406 \\
\hline 20 & Zona 20 & 66 & 8429 & 4626 \\
\hline 21 & Zona 21 & 123 & 9397 & 8599 \\
\hline 22 & Zona 22 & 21 & 6946 & 1463 \\
\hline 23 & Zona 23 & 27 & 5519 & 1888 \\
\hline 24 & Zona 24 & 199 & 2858 & 13930 \\
\hline 25 & Zona 25 & 115 & 4812 & 8087 \\
\hline \hline & Total & 1985 & 139266 & 139266 \\
\hline
\end{tabular}

\section{KESIMPULAN} berikut :

Proses pemodelan bangkitan dan tarikan perjalanan menghasilkan beberapa hal sebagai

- Menghasilkan rumus bangkitan perjalanan, yaitu $T P_{s m}=0,9157 S M-4,1372$ dengan $R^{2}=0,9665$.

- Perhitungan Kuat Tarik didasarkan pada Nilai Proporsi Kuat Tarik. Nilai Proporsi dihitung berdasarkan asumsi daya tarik Industri dan Sekolah. Dengan hasil kuat tarik terbesar di zona 17 yaitu 317 trip/jam, sedangkan terkecil di zona 4 yaitu 1 trip/jam.

- $\quad$ Nilai Bangkitan = Nilai Tarikan

- Total Bangkitan Perjalanan sejumlah 139.266 motor/jam, dengan hasil terbesar di zona 16 yaitu 15.906 motor/jam sedangkan terkecil di zona 1 yaitu 852 motor/jam.

- Total Tarikan Perjalanan sejumlah 139.266 motor/jam, dengan hasil terbesar di zona 17 yaitu 22.095 motor/jam sedangkan terkecil di zona 4 yaitu 70 motor/jam.

CATATAN. Penelitian ini dilakukan dengan survei dan pengamatan secara langsung di jam puncak pagi yaitu pada jam 06.00 - 09.00 WIB. Hasil pengamatan dijadikan dasar dalam asumsi proporsi kuat tarik sebagian besar adalah berangkat sekolah dan bekerja. 


\section{DAFTAR PUSTAKA}

Praditya, N.D.A. (2016). Pemodelan Transportasi Moda Sepeda Motor Kota Samarinda Untuk Tahun 2016. Tesis Magister Manajemen Rekayasa Transportasi. Institut Teknologi Sepuluh Nopember. Surabaya.

Suprayitno, H. \& Praditya, N.D.A. (2018). "Model Bangkitan Perjalanan Kota Samarinda Berbasis Zona Kecamatan”. Jurnal GEMA AKTUALITA. Vol. 7, No. 1:23-28.

Suprayitno, H. \& Ratnasari, V. (2017). "Reflexion on Linear Regression Trip Production Modelling Method for Ensuring Good Model Quality". AIP Conference Proceedings 1903 (1), 060013, 2017.

Suprayitno, H. \& Soemitro, R.A.A. (2018). "Preliminary Reflexion on Basic Principle of Infrastructure Asset Management”. Jurnal Manajemen Aset Infrastruktur \& Fasilitas. Vol. 2, Hal. : 1-9.

Tamin, O.Z. (2008). Perencanaan Pemodelan dan Rekayasa Transportasi - Teori Contoh Soal dan Aplikasi. Institut Teknologi Bandung. Bandung. 
(e)ISSN 2615-1847 (p)ISSN 2615-1839

Jurnal Manajemen Aset Infrastruktur \& Fasilitas - Vol. 2, Sup.2, Desember 2018 